Article

\title{
Immunogenic Properties of Recombinant Enzymes from Bothrops ammodytoides towards the Generation of Neutralizing Antibodies against Its Own Venom
}

\author{
Herlinda Clement ${ }^{1,2}$, Ligia Luz Corrales-García ${ }^{2,3}{ }^{\oplus}$, Damaris Bolaños ${ }^{2}$, Gerardo Corzo ${ }^{2, *}$ and \\ Elba Villegas $1, *(1)$ \\ 1 Centro de Investigación en Biotecnología, Universidad Autónoma del Estado de Morelos, Av. Universidad \\ 2001, Cuernavaca Mor 62209, Mexico; linda@ibt.unam.mx \\ 2 Departamento de Medicina Molecular y Bioprocesos, Instituto de Biotecnologia, Universidad Nacional \\ Autónoma de México, Avenida Universidad, 2001, Apartado Postal 510-3, Cuernavaca Mor 62210, Mexico; \\ ligia.corrales@udea.edu.co (L.L.C.-G.); damaris@ibt.unam.mx (D.B.) \\ 3 Departamento de Alimentos, Facultad de Ciencias Farmacéuticas y Alimentarias, Universidad de Antoquia, \\ AA 1226, Medellín 050010, Colombia \\ * Correspondence: corzo@ibt.unam.mx (G.C.); elbav@uaem.mx (E.V.)
}

Received: 16 October 2019; Accepted: 14 November 2019; Published: 2 December 2019

check for updates

\begin{abstract}
Bothropic venoms contain enzymes such as metalloproteases, serine-proteases, and phospholipases, which acting by themselves, or in synergism, are the cause of the envenomation symptoms and death. Here, two mRNA transcripts, one that codes for a metalloprotease and another for a serine-protease, were isolated from a Bothrops ammodytoides venom gland. The metalloprotease and serine-protease transcripts were cloned on a $\mathrm{pCR}{ }^{\circledR} 2.1-\mathrm{TOPO}$ vector and consequently expressed in a recombinant way in E. coli (strains Origami and M15, respectively), using pQE30 vectors. The recombinant proteins were named rBamSP_1 and rBamMP_1, and they were formed by an $\mathrm{N}$-terminal fusion protein of 16 amino acid residues, followed by the sequence of the mature proteins. After bacterial expression, each recombinant enzyme was recovered from inclusion bodies and treated with chaotropic agents. The experimental molecular masses for rBamSP_1 and rBamMP_1 agreed with their expected theoretical ones, and their secondary structure spectra obtained by circular dichroism were comparable to that of similar proteins. Additionally, equivalent mixtures of rBamSP_1, rBamMP_1 together with a previous reported recombinant phospholipase, rBamPLA2_1, were used to immunize rabbits to produce serum antibodies, which in turn recognized serine-proteases, metalloproteases and PLA2s from B. ammodytoides and other regional viper venoms. Finally, rabbit antibodies neutralized the 3LD50 of B. ammodytoides venom.
\end{abstract}

Keywords: antibodies; Bothrops ammodytoides; metalloprotease; protein expression; serine-protease; snake; venom; viper

Key Contribution: Production of neutralizing antibodies against B. ammodytoides envenomation, through immunogens, obtained from immunized animals with a mixture of recombinant phospholipase, serine-protease, and metalloprotease.

\section{Introduction}

Viper venoms are cocktails of toxic and non-toxic enzymes, as well as non-enzymatic proteins used both for constriction and ingestion of prey. Typical snake venom enzymes are L-amino acid oxidases, acetylcholinesterases, serine-proteases, phospholipases type A2, and metalloproteases [1]. Bothrops ammodytoides, a South American viperid from Argentina, has venom enzymes that produce 
dermonecrotic, inflammatory-edematogenic, and hemorrhagic effects in mice, and probably in humans [2]. Commercial antidotes or antivenoms against the bite of vipers contains antibodies that recognize such toxic enzymes, and neutralize them. Nowadays, antivenoms are generated by immunization of animals, regularly horses, using the whole venom of pit-vipers, having toxic or non-toxic components, in some cases being detrimental for such animals [3]. The immunogenicity of serine-proteases, metalloproteases, and phospholipases type A2, was assessed. Thus, the venom and glands of B. ammodytoides were used as a model to obtain such enzymes and then express them in a recombinant way. The aim was to develop neutralizing antibodies without the immunization of animals with the whole viper venom. The heterologous expression of such enzymes could support scientific research concerning the properties of venom toxic enzymes and, eventually, the enrichment of venom immunogens for the production of viperid antivenoms. Therefore, in this study, we report the cDNA cloning and recombinant production of a serine-protease (rBamSP_1) and a metalloprotease (rBamMP_1) from the venomous gland of $B$. ammodytoides. Furthermore, the recombinant serine-protease and metalloprotease, together with a previous reported recombinant phospholipase A2, from the same viperid species, were used as immunogens to generate rabbit antibodies, which reduced the enzymatic activities of proteases and phospholipases as well as neutralized the toxicity of B. ammodytoides venom. Therefore, here we communicate the proof of concept that a mixture of recombinant viper enzymes, specifically serine-proteases, metalloproteases, and phospholipases type A2, could be used as immunogens, instead of the whole venom, to generate neutralizing antibodies against pit-viper venoms, and such antibodies could be useful for bothropic antivenom studies.

\section{Results and Discussion}

\subsection{Isolation and Sequence Determination of rBamSP_1 and rBamMP_1}

The N-terminal sequence of the two enzymes was the starting point to design a set of synthetic primers used to amplify the sequences of serine-protease and metalloprotease from B. ammodytoides (see Materials and Methods). Applying polymerase chain reaction (PCR), we amplified both enzymes starting with the previously obtained cDNA. The purified inserts were cloned into plasmids $\mathrm{pCR}^{\circledR} 2.1-\mathrm{TOPO}^{\circledR}$ and then into the plasmid pQE30 (Figure S1). The sequence of amino acid of the cloned rBamSP_1 and rBamMP_1 are shown (Tables 1 and 2). rBamSP_1 preserves the highly conserved residues His56, Asp100 and Ser197, of the common serine-protease active site (Table 1, bold); apparently, a characteristic of snake venom-type thrombin-like enzyme and rBamMP_1 has a consensus zinc-binding motif HEXGHXXGXXHD (Table 2, bold) [4].

Table 1. Amino acids residues of rBamSP_1 and alignment to similar viper enzymes.

\begin{tabular}{ll}
\hline \multicolumn{1}{c}{ rBamSP_1 } & \multicolumn{1}{c}{ Sequence $^{1}$} \\
\hline rBamSP_1 & VIGGDECNINEHPFLVALYTSRSRRFHCGGTLINQEWVLTAAHCDRKNIRIKLGMHSKN \\
Q7T229.1 & IIGGDECNINEHRFLVALYTSRSRRFHCSGTLINQEWVLTAANCDRKNIRIKLGMHSKN \\
AUS82526.1 & IIGGEECNINEHRFLVALYTFRSKRFHCSGTLINQEWVLTAAHCDRKNIRIKLGMHSTN \\
& \\
rBamSP_1 & VTNEDEQTRVPKEKFFCLSSKTYTKWDKDIMLIRLKRPVNDSPHIAPLSLPSNPPSVGS \\
Q7T229.1 & VTNEDEQTRVPKEKFFCLSSKTYTKWDKDIMLIRLKRPVNDSPHIAPISLPSSPPSVGS \\
AUS82526.1 & VTNEDAQTRVPKEKFFCLSSKTYTKWDKDIMLIRLKRPVNNSAHIATLSLPSNPPSLGS \\
rBamSP_1 & VCRIMGWGTISPTKVSYPDVPHCANINLLDYEVCRTAHGGLPATSRTLCAGILEGGKDS \\
Q7T229.1 & VCRIMGWGTISPTKVSYPDVPHCANINLLDYEVCRAAHGGLPATSRTLCAGILEGGKDS \\
AUS82526.1 & VCRIMGWGTISATKETYPDVPHCANINILDYEVCRAAHGGLPATSRTLCAGILKGGKDS \\
& 197 \\
rBamSP_1 & CQGDSGGPLICNGQFQGILSWGVHPCGQRLKPGVYTKVFDYTEWIRSIIAGNTDVTCPP \\
Q7T229.1 & CQGDSGGPLICNGQFQGILSWGVHPCGQRLKPGVYTKVSDYTEWIRSIIAGNTDVTCPP \\
AUS82526.1 & CKGDSGGPLICNGEIQGIVSWGAHPCGQSLKPGVYTKVFDYTEWIQSIIAGNTDATCPP \\
\hline 229.1 and AUS82526.1 are serine-proteases from Bothrops jararacusSu and Crotalus mitchellii, with 96.6\% and \\
\% of identity to rBamSP_1, respectively. The residues in bold in positions His56, Asp100 and Ser197 represent
\end{tabular}


Table 2. Amino acids residues of rBamMP_1 and alignment to similar viper enzymes.

\begin{tabular}{ll}
\hline \multicolumn{1}{c}{ rBamMP_1 } & \multicolumn{1}{c}{ Sequence $^{\mathbf{1}}$} \\
\hline rBamMP_1 & EQQRYNPYKYVEFCIVVDQGTVTKNNGDLDKIKTRIYELVNTVNEIYRYMYIHVALVCL \\
P30431.1 & EQQRYDPYKYIEFFVVVDQGTVTKNNGDLDKIKARMYELANIVNEIFRYLYMHVALVGL \\
ALB00542.1 & EQQKYNPFRYIEFLLVVDQGMVTKNNGDLDKIKARMYELANIVNEIFRYLYMHAALVGL \\
& \\
rBamMP_1 & ETWSNGDKITVKPDVDYTWKSFAEWRKTVLLTRKNHDNAQLLTAIDFSGPTIGYAYIAT \\
P30431.1 & EIWSNGDKITVKPDVDYTLNSFAEWRKTDLLTRKKHDNAQLLTAIDFNGPTIGYAYIGS \\
ALB00542.1 & EIWSNGDKITVKPDVDYTLNSFAEWRKTDLLTRKKHDNAQLLTAIDFNGPTIGYAYIGS \\
& \\
rBamMP_1 & MCDPKSSVGIVQDFSPINLLVAVTMAHEMGHNLGIHHDRGSCSCGGYPCIMGPVISNEP \\
P30431.1 & MCHPKRSVGIVQDYSPINLVVAVIMAHEMGHNLGIHHDTGSCSCGDYPCIMGPTISNEP \\
ALB00542.1 & MCHPKRSVAIVQDYSPINLVMAVIMAHEMGHNMGIHHDTGSCSCGDYPCIMGPTISNEP \\
& \\
rBamMP_1 & SKFFSNCSYIQCWDFIMNHNPECIVNEPLGTDIVSPPVCGNELL \\
P30431.1 & SKFFSNCSYIQCWDFIMNHNPECIINEPLGTDIISPPVCGNELL \\
ALB00542.1 & SKFFSNCSYIQCWDFIMNHNPECIINEPLGPDIVSPPVCGNELL \\
\hline
\end{tabular}

${ }^{1}$ P30431.1and ALB00542.1are metalloproteases from Bothrops jararaca and Bothrops atrox, with $86.4 \%$ and $83.2 \%$ of identity to rBamMP_1, respectively. The residues in bold positions 145-156, HEMGHNLGIHHD, represent the zinc binding motif of metalloproteases.

\subsection{Expression of rBamSP_1 or rBamMP_1, Their Purification and Folding}

The genes of rBamSP_1 or rBamMP_1 were cloned in pQE30 plasmids, respectively, which generates proteins with a 6 His-tag attached to the $\mathrm{N}$-terminal region, allowing a fast purification of the recombinant proteins by nickel affinity agarose columns (NiNTA). We also added a recognition site for the peptidase FXa, located between the 6His-tag and the enzyme sequence of rBamSP_1 or rBamMP_1, in case of potentially harmful influence of the tag toward the biological activity. Heterologous expression of either rBamSP_1 or rBamMP_1 was achieved using E. coli Origami and M15 strains, respectively (Figure S2). rBamSP_1 or rBamMP_1 were predominantly located in inclusion bodies (Figure S2A, lane 2 for rBamSP_1, and Figure S2B lane 4 for rBamMP_1), and were recovered by NiNTA (Figure S2A, lanes 7-13 for rBamSP_1 and Figure S2B lanes 8-14 for rBamMP_1). The heterologous expression of either rBamSP_1 or rBamMP_1 from inclusion bodies, as well from NiNTA purification, was verified through Western blot, utilizing an anti-6His-tag antibody, joined to alkaline phosphatase. Either rBamSP_1 or rBamMP_1 was subjected to in vitro folding and then a reversed-phase high-performance liquid chromatography (RP-HPLC) purification. All the fractions with retention times fluctuating from 34 to $40 \mathrm{~min}$ (linear-gradient, $10 \%-60 \%$ of B in $50 \mathrm{~min}$ ) were gathered (Figure 1). Sodium dodecyl sulfate polyacrylamide gel electrophoresis (SDS-PAGE, 12\%) confirmed that the collected fractions possessed the expected molecular mass. Furthermore, either rBamSP_1 or rBamMP_1 showed the experimental molecular masses 27,849.3 and 26,830.2 (Figure S3A,B), which were acquired by mass spectrometry and corresponded to the predicted molecular masses of enzymes 6His-tagged. The results indicated that the fractions collected from the RP-HPLC purification corresponded to rBamSP_1 or rBamMP_1; although, the enzymes contain 12 and 10 cysteines, and they could probably produce up to 10,395 and 945 different cysteine linked isoforms, respectively, regarding combining disulfide pairing probabilities. Evidently, the cellular system in the snake venom gland dictates the establishment of accurate protein folding of native enzymes when compared to a heterologous expression system. The protein yield of rBamSP_1 and rBamMP_1, were 1 and $1.8 \mathrm{mg} / \mathrm{L}$, respectively. 

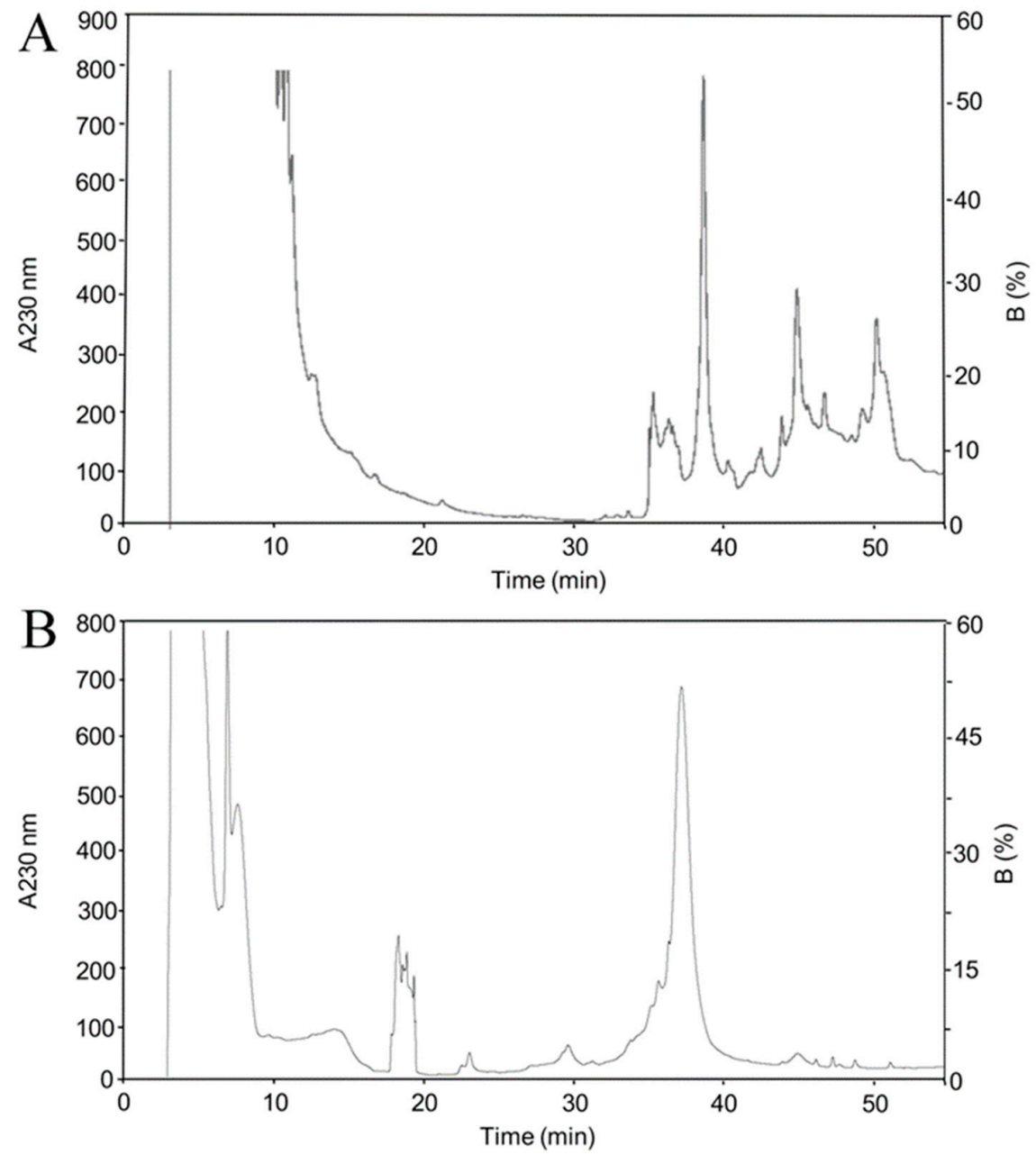

Figure 1. Chromatographic separation after Ni purification. (A) rBamSP_1; (B) rBamMP_1. The high-performance liquid chromatographic (HPLC) separations of either rBamSP_1 or rBamMP_1, obtained after elution from affinity chromatography ( $400 \mathrm{mM}$ imidazole). The recombinant proteins were fractionated using an analytic C4 column (Vydac 214 TP $4.6 \times 250 \mathrm{~mm}$, reverse-phase, USA) with solvent A ( $0.1 \%$ trifluoroacetic acid, TFA, in water), and solvent B ( $0.1 \%$ TFA in acetonitrile). From 10 to $60 \%$ of the B-solvent was run for $50 \mathrm{~min}$ at $1 \mathrm{~mL} / \mathrm{min}$, the fractions were detected at $230 \mathrm{~nm}$. The different fractions were examined by mass spectrometry.

\subsection{Secondary Structure of rBamSP_1 and rBamMP_1}

Circular dichroism (CD) was used to analyze the recombinant serine- and metalloprotease; the aim was to confront their secondary structures upon those already reported. The results showed significant absorption for $\alpha$-helix and $\beta$-strand content (secondary structures) (Figure 2). In agreement with the CD deconvolution software [5], the secondary structure was $35.2 \%, 12.6 \%, 7.5 \%, 44.7 \%$ and $20.7 \%, 26.4 \%$, $14.0 \%$ and $38.9 \%$ of $\alpha$-helix, $\beta$-strands, turns and random coil structure for rBamSP_1 and rBamMP_1, respectively. Until now, all pit-viper venom serine- and metalloproteases comprise a higher balance of $\alpha$-helix, which is described by a positive band $(198 \mathrm{~nm})$ and a negative ellipticity (208-222 nm) [6]. Also, they contain a higher proportion of $\beta$-strands. Here, rBamSP_1 and rBamMP_1 showed similar patterns to the Bothrops jararacussu serine protease (PDB: 4GSO) and Daboia siamensis metalloprotease (PDB: $2 \mathrm{E} 3 \mathrm{X})$, respectively. As reported earlier, the recombinant $\mathrm{rBamPLA}_{2} 1$ shows also secondary structure similar to the native pit-viper phospholipases [7]. Overall, the three recombinant proteins agreed with the canonical secondary structures of phospholipases and proteases from viper venom $[6,7]$. 


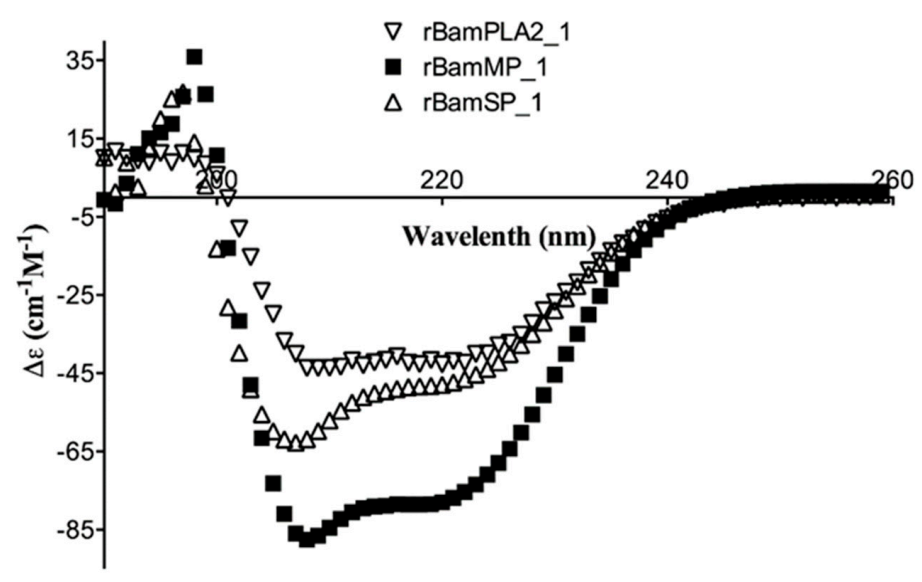

Figure 2. Circular dichroism (CD) of recombinant proteins rBamSP_1, rBamMP_1 and rBamPLA 2_1.

\subsection{Rabbit Immunization, Antibody Recognition and Titers}

Rabbits were immunized with $10 \mathrm{mg}$ of a blend of recombinant enzymes rBamSP_1, rBamMP_1, and rBamPLA $2_{-} 1$. The rabbits were bled after 5 months of immunization, and the serum was evaluated in its capacity to recognize each recombinant enzyme, and also the native enzymes from Bothrops venoms. Figure $3 \mathrm{~A}$ presents the venoms protein pattern from different species of Bothrops, where serine-proteases, metalloproteases, and phospholipases are evident from their apparent molecular masses (red triangle marks in Figure 3A,B). Figure 3B illustrates how rabbit antibodies recognize proteins of venom from different Bothrops species. We perceived antibody-recognition for a wide span of proteins, which represents the native serine-proteases, metalloproteases, and PLA2s from Bothrops venoms. Furthermore, the same rabbit serum antibodies were used to titer the antibody recognition against several bothropic venoms, Figure 4 presents the rabbit antibody titers toward the recombinant enzymes and the venom of other Bothrops species. Table 3 shows that the recombinant enzymes were the most recognized as expected, and among them, the recombinant phospholipase had the higher titers followed by that of the serine- and metalloproteases. Concerning recognition of rabbit IgGs to pit-viper venoms such B. ammodytoides, B. diporus, B. jararacussu, B. moojeni, B. alternatus, and B. asper, the venoms of $B$. ammodytoides and B. moojeni were the most recognized with titer values of 543 and 624, respectively (Table 3, see Section 4.9. Enzyme-Linked Immuno Sorbent Assay (ELISA) in the Material and Methods). However, the antibody recognition was very evident; the EC50 (half-maximal effective concentration) was considerably low for B. asper and B. diporus (85 and 90, respectively. Table 3). Nevertheless, the rabbit antibodies were capable of reducing the enzymatic activities of proteases and phospholipases from $B$. ammodytoides venom. Figure 5 shows the phospholipase activity of $B$. ammodytoides venom in the absence and presence of IgGs from immunized rabbits. Likewise, Figure 6 shows the B. ammodytoides venom protease activity in a gelatine zymogram in the absence and presence of IgGs from immunized rabbits. This data proves that rBamSP_1, rBamMP_1, and rBamPLA2_1 could be used as immunogens for producing rabbit antibodies to decrease phospholipase and protease activities, which are related to pit-viper venom poisonous activities, such as myotoxicity or restraint to platelet function that conducts to death, at least with the venom of B. ammodytoides.

The reactivity of the antibodies anti-rBamSP_1, rBamMP_1, and rBamPLA2_1 over other Bothrops venoms may also heighten the interest in the research on the potential neutralization of harmful activities by recombinant enzymes as immunogens. Currently, the production of anti-snake venom for healing objectives are obtained in form of polyclonal antibodies generated in large vertebrates, often applying whole venom from a viper as immunogen; other strategies are being analyzed [8], for example, the heterologous proteins obtained through molecular biology techniques, could be used for the production of polyclonal or monoclonal antibodies or neutralizing fragments, which may indicate future and interesting approaches for anti-venom production $[9,10]$. 
Table 3. Titers of antibodies from rabbits against the recombinant enzymes and Bothrops venoms.

\begin{tabular}{lcc}
\hline \multicolumn{1}{c}{ Protein } & Titers & CI $^{\mathbf{1}}$ \\
\hline rBamPLA 2 1 & 17,148 & $15,705-18,723$ \\
rBamSP_1 & 10,673 & $9063-12,568$ \\
rBamMP_1 & 2653 & $2040-3451$ \\
B. ammodytoides & 543 & $475-620$ \\
B. jararacussu & 120 & $104-138$ \\
B. diporus & 90 & $81-100$ \\
B. moojeni & 624 & $572-679$ \\
B. alternatus & 159 & $138-182$ \\
B. asper & 85 & $80-91$ \\
\hline \multicolumn{3}{c}{${ }^{1}$ Confidence intervals (95\%). }
\end{tabular}

A

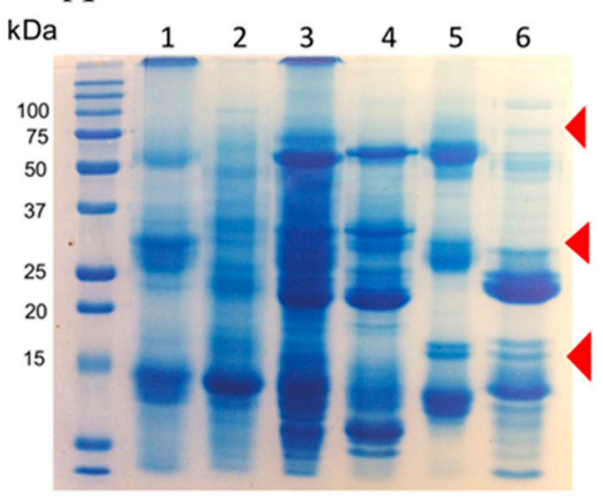

B

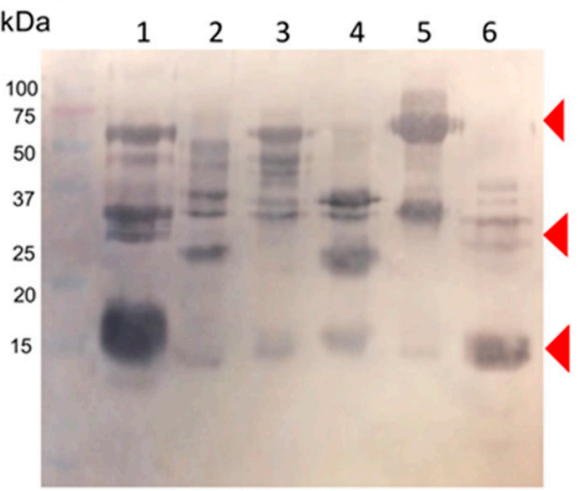

Figure 3. The proteins present in venoms samples from various species of Bothrops exposed in (A). sodium dodecyl sulfate (SDS) gel and (B). Western blot. Lanes, (1) B. ammodytoides; (2) B. jararacussu; (3) B. diporus; (4) B. moojeni; (5) B. alternatus; (6) B. asper. Each line of the SDS gel had $50 \mu \mathrm{g}$, and $10 \mu \mathrm{g}$ in each line of the Western-blot (rabbit IgG anti-mixture of recombinant enzymes (rBamSP_1, rBamMP_1, and rBamPLA2_1) was the first antibody, and rabbit IgG coupled to alkaline phosphatase was the second antibody).

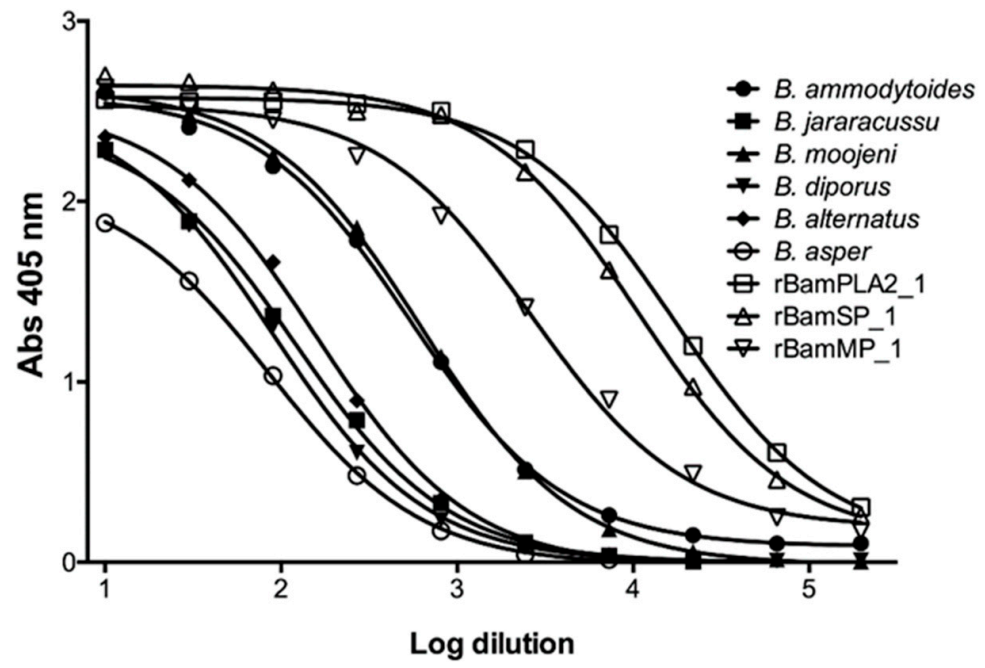

Figure 4. Antibody recognition of rabbit IgGs towards venoms of different Bothrops species. Titers of rabbit anti-recombinant enzymes (rBamSP_1, rBamMP_1, and rBamPLA2_1) against various venoms of Bothrops species, and also towards the recombinant enzymes used as immunogens. 


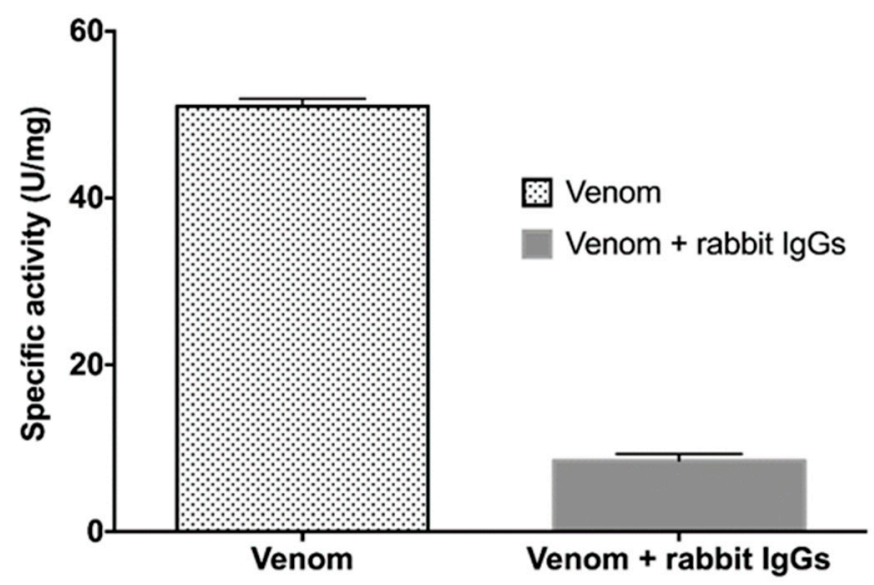

Figure 5. Phospholipase activity in the presence of rabbit IgGs. Titrimetric assays of PLA 2 activity of $B$. ammodytoides venom, and inhibition of the same venom with the rabbit IgGs obtained from the immunization with rBamSP_1, rBamMP_1 and rBamPLA 2 1. The specific activity is given in U/mg $=\mu \mathrm{mol}$ of $\mathrm{NaOH}$ consumed per minute per milligram of venom. Error bars express the standard deviation of three experiments.

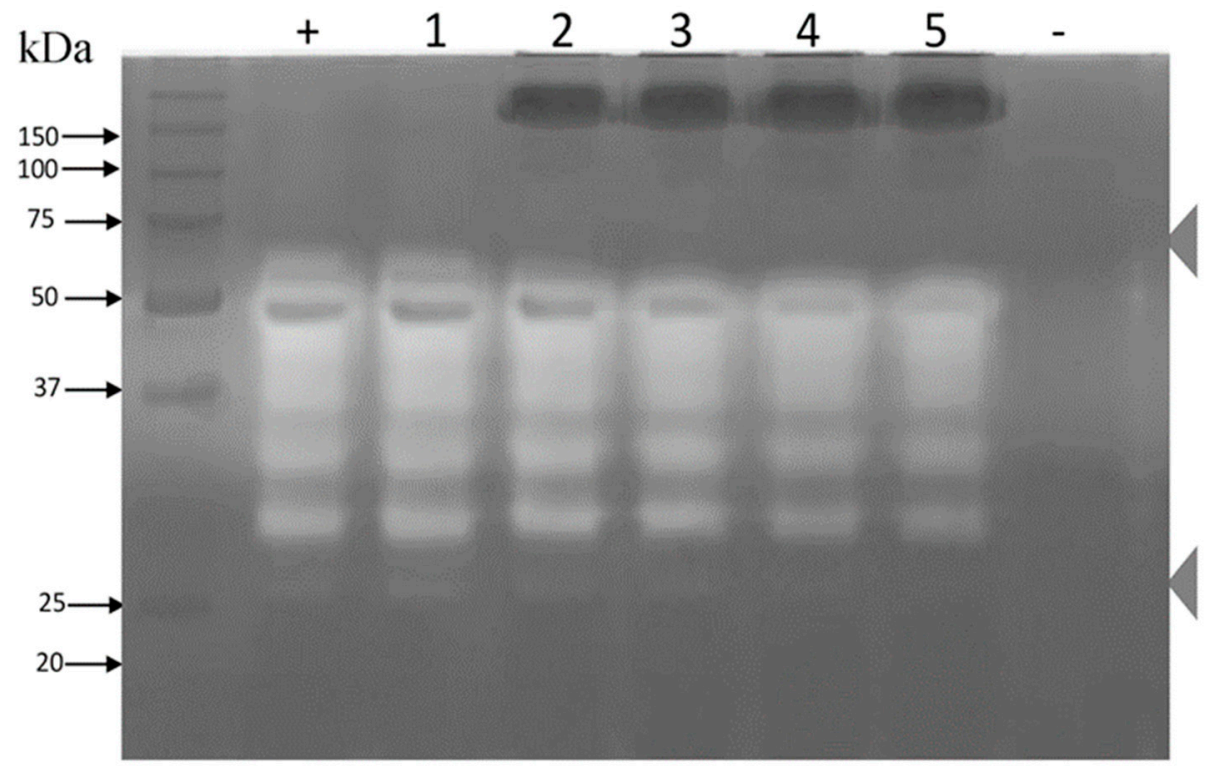

Figure 6. Zymogram of protease inhibition in the presence of rabbit IgGs. A $12 \%$ sodium dodecyl sulfate polyacrylamide gel electrophoresis (SDS-PAGE) gel with $1.5 \mathrm{mg} / \mathrm{mL}$ gelatin was generated. The whole venom of B. ammodytoides was used at $15 \mu \mathrm{g} /$ well in all loading wells. Lanes (+) and (1) venom; (2) venom plus $50 \mu \mathrm{g}$ of rabbit IgG; (3) venom plus $100 \mu \mathrm{g}$ of rabbit IgG; (4) venom plus $150 \mu \mathrm{g}$ of IgG; and (5) venom plus $200 \mu \mathrm{g}$ of rabbit IgG; (-) Control of phosphate-buffered saline (PBS) $1 \times$. The zymogram was incubated overnight at room temperature.

\subsection{Immunoaffinity Chromatography and Venom Neutralization}

Intended to deep into antibody recognition and venom neutralization, immunoaffinity chromatography was performed, which is generally used in antivenomics for the analysis of the quality of antibodies when bound to animal venoms [11]. Figure 7A shows the HPLC profile of the B. ammodytoides venom. Here, the immunoaffinity chromatography (Figure $7 \mathrm{~B}, \mathrm{C}$ ) using a ligand density ( $\mathrm{mg} \mathrm{IgG/mL} \mathrm{of} \mathrm{the} \mathrm{matrix)} \mathrm{significantly} \mathrm{showed} \mathrm{the} \mathrm{union} \mathrm{of} \mathrm{venom} \mathrm{enzymes} \mathrm{to} \mathrm{the} \mathrm{rabbit} \mathrm{antibodies,}$ which recognized metalloproteases, serine-proteases and phospholipases from B. ammodytoides venom (inside, Figure 7C, Table S1). The information obtained here could be valuable for obtaining a 
better comprehension of venom protein immunogenicity, antivenom strength, and for improving antivenom quality.

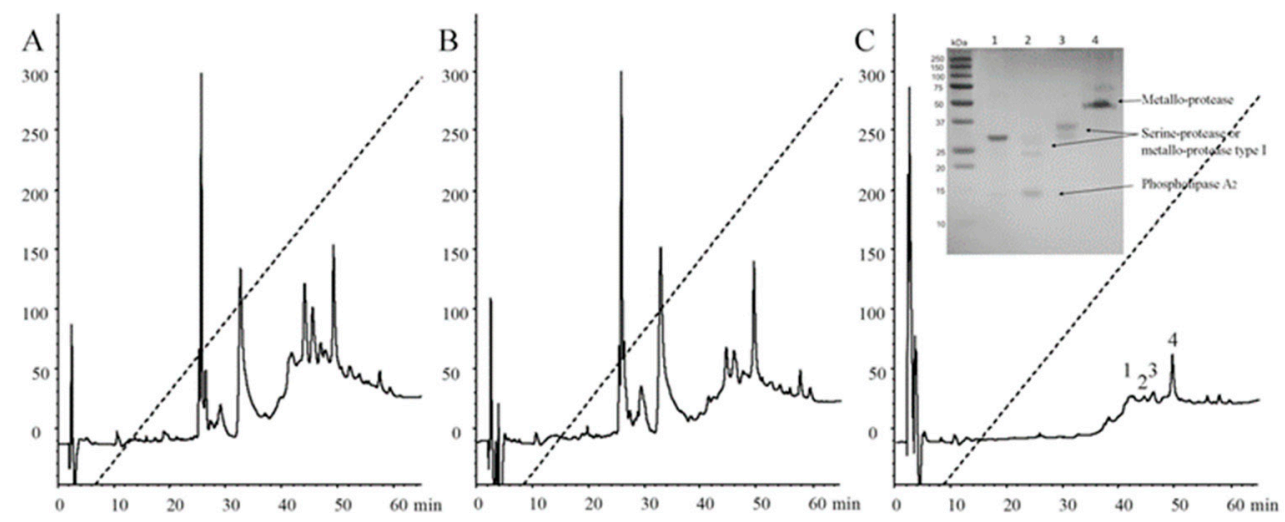

Figure 7. Reversed-phase high-performance liquid chromatography (RP-HPLC) profiles of Bothrops ammodytoides venom and protein fractions after immunoaffinity chromatography. (A) Complete venom of Bothrops ammodytoides; (B) Venom no bound to immunoaffinity column; and (C) Venom bound. The complete venom and the proteins eluted after immunoaffinity chromatography were fractioned by using an analytic C8 column (reverse-phase) with solvent (A) (0.1\% trifluoroacetic acid, TFA, in water), and solvent (B) (0.1\% TFA in acetonitrile). From 0 to $60 \%$ of the B-solvent was run for $60 \mathrm{~min}$ at 1 $\mathrm{mL} / \mathrm{min}$, the fractions were detected at $280 \mathrm{~nm}$. For protein identification of caption in (C), please see Section 4.12. Immunoaffinity chromatography.

The practical estimation of antivenoms is established upon its capacity to neutralize the harmful impact of venoms $\left(\mathrm{LD}_{50}\right)$. Consequently, to observe venom neutralization by the rabbit IgGs, the $\mathrm{LD}_{50}$ for B. ammodytoides venom was determined, which was $18.6 \mu \mathrm{g}$ of venom $/ \mathrm{mouse}(0.93 \mathrm{mg} / \mathrm{kg}$ mouse). Considering the interspecific variation in the composition of the snake venom, the previous value is within the $\mathrm{LD}_{50} \mathrm{~s}$ reported from Bothrops venom, which are ranging from 0.66 to $232 \mathrm{mg} / \mathrm{kg}$ mouse [12-15]. Afterwards, the rabbit anti-recombinant enzyme IgGs were challenged with 3LD50 (55.8 $\mu \mathrm{g} / \mathrm{mouse})$ of B. ammodytoides venom, according to the World Health Organization (WHO) [16]. The IgGs from the anti-recombinant enzymes neutralized the lethality of $B$. ammodytoides venom with an $\mathrm{ED}_{50}$ of $13.1 \mathrm{mg} \mathrm{IgGs} /$ mouse $(\mathrm{n}=3)$, meaning $55.8 \mu \mathrm{g}$ of whole $B$. ammodytoides venom neutralized by $13.1 \mathrm{mg}$ of anti-recombinant enzymes IgGs; that is, an EaV value of $4.3 \mu \mathrm{g}$ of venom/mg of IgGs (233 $\mathrm{mg}$ of IgGs/mg of venom). Although few communications had reported the specific activity of IgG anti-venoms, some specific activity values from commercial antivenoms (obtained from horse IgGs) are from 2.8 to $26.8 \mathrm{mgAv} / \mathrm{mg}$ B. asper venom) [12,15].

\section{Conclusions}

This work presents the proof of the concept of the use of a mixture of recombinant enzymes (metalloprotease, serine-protease, and phospholipase) to produce antibodies against native venom enzymes from species of Bothrops. The circular dichroism spectra of the venom enzymes here heterologously expressed indicate that the secondary structure of such recombinant enzymes is maintained, even though some isoforms having different disulfide pairings could take place, and such structures could produce antibodies against native enzymes. Such recombinant proteins are immunogenic, they yield neutralizing antibodies against B. ammodytoides venom, and such antibodies recognize related enzymes from other Bothrops venoms. Neutralization of whole animal venoms or venom components such as elapids (Micrurus, Dendroapsis, Naja), scorpions (Centruroides, Tityus, Androctonus) and spiders (Loxoceles), using antibodies raised up by recombinant proteins such as immunogens, has been already reported [7-10]. Likewise, recombinant enzymes from viperids could be employed to produce antibodies to neutralize the toxicity of envenomation, such as platelet alterations 
and myotoxicity, both generated by venom from related Bothrops vipers. In fact, since the amino acid domains into metalloproteases, serine-proteases, and phospholipases are mostly conserved in other bothropic venoms, here we postulate that this experimental antivenom could neutralize or retard the venom activity of such Bothrops species.

\section{Materials and Methods}

\subsection{Venom Gland and Venom}

Adult exemplars of B. ammodytoides were maintained in healthy conditions and clean boxes, at 27 ${ }^{\circ} \mathrm{C}$ (constant temperature) with cycles of $12 \mathrm{~h}$ of light and dark. Every fortnight the animals were fed, and water was administered ad libitum. The venom was manually collected, and at once, dried under vacuum and saved at $-20^{\circ} \mathrm{C}$ for further use. A healthy B. ammodytoides snake was selected to obtain a single venom gland (one or two). The animal was anesthetized, and by chirurgical extraction, the gland was removed and treated instantaneously with RNAlater ${ }^{\circledR}$ (Thermofisher, Asheville, NC, USA) and saved at $-70{ }^{\circ} \mathrm{C}$ till use. Following the chirurgical procedure, the snake was recovered and remained healthy.

\subsection{Bacterial Strains, Enzymes and Plasmids}

For DNA cloning and plasmid proliferation, we used the XL1-Blue Escherichia coli strain. E. coli strains, Origami or M15, were used for the expression of recombinant serine-protease and metalloprotease, respectively. Plasmids $\mathrm{pCR}^{\circledR}{ }^{\circledR}$ 2.1-TOPO ${ }^{\circledR}$ (Invitrogen, Carlsbad, CA, USA), and pQE30 (Qiagen, Valencia, CA, USA) were employed for cloning the genes and the expression of the 6His-tagged recombinant proteins, respectively. Factor Xa protease (FXa), restriction enzymes, T4 DNA ligase, and Taq polymerase, were acquired from New England Biolabs (NEB, Ipswich, MA, USA).

\subsection{RNA Extraction and Gene Assembly}

“Total RNA Isolation System" (Qiagen, Valencia, CA, USA) was used to extract the total RNA from the venom gland. The N-terminal sequence of enzymes, which allowed us to design specific oligonucleotides, and all of them used to amplify (by 3'RACE) a cDNA of 707 bp and 662 bp of rBamSP_1 and rBamMP_1, respectively [17]. The oligonucleotides were labeled as Oligo1 Fw serine-protease (GTCATTGGAGGTGATGAATGT, Tm $60^{\circ} \mathrm{C}$ ), Oligo AUAP from 3’RACE kit (GGCCACGCGTCGACTAGTAC), Oligo 1 Fw metalloprotease (GAGCCCATCAAAAAGGCC, $\operatorname{Tm} 56^{\circ} \mathrm{C}$ ) and Oligo $1 \mathrm{Rv}$ metalloprotease (GGCATCGAAGCGATTTCT, Tm $58^{\circ} \mathrm{C}$ ).

After each construction and transformation, some clones were picked and analyzed upon the molecular biology protocols. The recombinant gene was confirmed by plasmid sequencing (plasmid purification by the High Pure Plasmid Isolation Kit, Roche, Basel, Switzerland).

\subsection{Plasmid Construction for Protein Expression}

The genes of enzymes rBamSP_1 and rBamMP_1 also included the recognition sequences for both restriction enzymes $(B a m \mathrm{HI}$ and $P s t \mathrm{I})$ and protease FXa. The digested inserts were ligated into the expression vector pQE30 using the same restriction sites, BamHI and PstI. The pQE30 vector contains a tag of polyhistidine (6His) to assist in protein purification by affinity chromatography. Between the 6 His-tag and the toxin was placed the FXa cleavage site, intended to obtain the entire native protein if necessary (Figure S1). The constructions in pQE30 were confirmed by DNA sequencing. Competent E. coli Origami and M15 cells were transformed with the vector corresponding to each enzyme by the following procedure: incubation for $30 \mathrm{~min}$ on ice, heat-shocked at $42^{\circ} \mathrm{C}$ for $1 \mathrm{~min}$, and finally, incubation in ice for $5 \mathrm{~min}$. The transformed cells were grown at $37^{\circ} \mathrm{C}$ for one $\mathrm{h}$ in super optimal broth with catabolite repression (SOC) medium and then poured on Luria Broth (LB) agar, including $100 \mu \mathrm{g} / \mathrm{mL}$ of ampicillin. 


\subsection{Expression and Purification of the Enzymes rBamSP_1 and rBamMP_1}

The E. coli Origami strain harboring the plasmid pQE30rBamSP_1 or E. coli M15 strain transformed with the plasmid pQE30rBamMP_1 were cultivated in LB liquid medium. Once a given bacterial culture reached an optical density (OD600) of 0.8 absorption units, it was supplemented with $0.5 \mathrm{mM}$ isopropyl-ß-D-thiogalactopyranoside (IPTG) and incubated at $16{ }^{\circ} \mathrm{C}$ for $24 \mathrm{~h}$. Afterward, the culture was centrifuged (7168 $\times g$ for $20 \mathrm{~min}$ in JA-14 rotor, Beckman model J2-21). Cells were resuspended in washing buffer (Tris-HCl $0.05 \mathrm{M}, \mathrm{pH} 8.0$ ) and disrupted using the protein extraction reagent BugBuster ${ }^{\circledR}$ (Novagen, Germany). The resulting cell debris were centrifuged $(16,128 \times g$ for $20 \mathrm{~min})$, the soluble fraction was discarded, and the insoluble fraction was reused.

The insoluble fraction was cleaned doubly using the washing buffer and then centrifuged at $16,128 \times \mathrm{g}$ for $20 \mathrm{~min}$. The insoluble fraction contained the inclusion bodies, which were resuspended and solubilized in guanidinium chloride solution ( $\mathrm{GndHCl} 6 \mathrm{M}$, Tris- $\mathrm{HCl} 0.05 \mathrm{M}, \mathrm{pH} 8.0$ ). The solution was centrifuged at $16,128 \times g$ for $20 \mathrm{~min}$; after centrifugation, the insoluble material was removed. The supernatant solution, which contained the recombinant protein, was purified by affinity column chromatography that included a Ni-NTA (Ni-nitrilotriacetic acid) resin. The system was equilibrated with buffer $\mathrm{A}^{\prime}(\mathrm{GndHCl} 6 \mathrm{M}$, Tris- $\mathrm{HCl} 0.05 \mathrm{M}, \mathrm{pH} 8.0)$, and the recombinant proteins were eluted with buffer B' (GndHCl 6M, Tris-HCl 0.05M, imidazole $400 \mathrm{mM}, \mathrm{pH} 8.0)$. The eluted samples were subjected to the second purification step, reversed-phase HPLC (RP-HPLC) using an analytical C4 reversed-phase column (Vydac 214 TP 4.6x250 mm, Hesperia, CA, USA), and applying a linear gradient with solvent A $(0.1 \%$ trifluoroacetic acid, TFA, in water) and solvent B ( $0.1 \%$ TFA in acetonitrile). The linear gradient was run from 10 to $60 \%$ solvent $B$ for $50 \mathrm{~min}$ at $1 \mathrm{~mL} / \mathrm{min}$. Eluted proteins, detected at $230 \mathrm{~nm}$, were collected, and immediately lyophilized.

\subsection{Molecular Mass Determination}

The molecular masses of the enzymes were validated by mass spectrometry analysis. Fractions of rBamSP_1, collected from RP-HPLC, were lyophilized, and then, concentrated to $500 \mathrm{pmol} / 5 \mu \mathrm{L}$ with a solution of acetonitrile $50 \%$ and acetic acid $1 \%$. Samples were directly injected into a Thermo Scientific LCQ Fleet ion trap mass spectrometer (San Jose, CA, USA) with a Surveyor MS syringe pump delivery system. The samples were run at $10 \mu \mathrm{L} / \mathrm{min}$, and they were split to introduce only $5 \%$ of the sample into the nanospray source $(0.5 \mu \mathrm{L} / \mathrm{min})$. The spray voltage and capillary temperature were fixed at $1.5 \mathrm{kV}$ and $150^{\circ} \mathrm{C}$, respectively. The fragmentation source was operated at $25-35 \mathrm{~V}$ of collision energy, 35-45\% (arbitrary units) of normalized collision energy, and all spectra were gathered in the positive-ion mode. Data acquisition and deconvolution were made on the Xcalibur Windows NT PC data system. For rBamMP_1, samples were desalted with Zip Tip C4 (Millipore; Billerica, MA, USA), and injected to an LC-MS (liquid chromatography-mass spectrometry) system composed of an Accela Pump (Thermo-Fisher Co, San Jose, CA, USA) coupled to a LTQ-Orbitrap Velos mass spectrometer (Thermo-Fisher Co., San Jose, CA, USA) with a nano-electrospray (ESI) ionization source. The nano-flow liquid chromatography consisted of an isocratic system of $50 \%-50 \%$ of solvents A (water) and B (acetonitrile), both with $0.1 \%$ formic acid with a running time of $20 \mathrm{~min}$. A homemade hair needle (ID $0.75 \mu \mathrm{m}$ and $20 \mathrm{~cm}$ long) was used, and the flow of the LC system was $300 \mathrm{~nL} / \mathrm{min}$.

\subsection{Circular Dichroism}

Secondary structure spectra of rBamSP_1 and rBamMP_1 were registered at room temperature in quartz cells (1 mm-path) from 190 to $260 \mathrm{~nm}$ employing a spectropolarimeter Jasco J-710 (Jasco, Japan). Individually protein was dissolved in trifluoroethanol (60\%) to obtain a concentration of $0.6 \mathrm{mg} / \mathrm{mL}$. The delta CD absorbances were collected every $1 \mathrm{~nm}$ at a speed of $20 \mathrm{~nm} / \mathrm{min}$. The CD values corresponded to the average of three different $C D$ registrations, and they were examined using the algorithms presented online at the BeStSel (Beta Structure Selection) [5]. 


\subsection{Animal Immunizations}

Rabbits were hyperimmunized by the subcutaneous way, with $10 \mathrm{mg}$ of a blend of the three recombinant enzymes rBamSP_1, rBamMP_1, and rBamPLA2_1, 10/3 mg each, to produce serum antibodies. The immunization protocols started with the administration of a dose of $0.1 \mathrm{mg}$ of the mixed proteins into the Complete Freud's Adjuvant (CFA); afterward, increasing doses up to $0.25 \mathrm{mg}$, and shifting with incomplete Freud's (IFA) and aluminum hydroxide (AH), were administered during one month. Immunizations were made every two weeks, with $0.5 \mathrm{mg}$ of the mixed proteins. The serum from rabbits $(\mathrm{n}=3)$ was pooled, and antibodies were obtained from the plasma through caprylic acid precipitation (5\%) [18]. A final solution of rabbit-derived immunoglobulins containing $50 \mathrm{mg} / \mathrm{mL}$ of protein was used for further experiments.

\subsection{Enzyme-Linked Immunosorbent Assay (ELISA)}

Enzyme-linked immunosorbent assays (ELISA) were run, according to Clement et al. [7]. Briefly, solid-phase-adsorbed rBamSP_1, rBamMP_1 or rBamPLA2_1 were prepared by treating wells of MaxiSorp plates (NUNC' ${ }^{\text {TM }}$, Thermo Scientific, Waltham, MA, USA) with $100 \mu \mathrm{L}$ of a solution of the recombinant protein $(5 \mu \mathrm{g} / \mathrm{mL})$ in $0.1 \mathrm{M}$ sodium carbonate buffer $(\mathrm{pH} 9.6)$. After incubation at $4{ }^{\circ} \mathrm{C}$ overnight, wells were emptied and washed three times with $200 \mu \mathrm{L}$ of washing buffer (Tris- $\mathrm{HCl} 0.05 \mathrm{M}$, $\mathrm{pH} 8$, Tween-20 $0.5 \mathrm{mg} / \mathrm{mL}$, and $\mathrm{NaCl} 0.15 \mathrm{M}$ ). Then, the wells were loaded with $200 \mu \mathrm{L}$ of blocking buffer (gelatin $5 \mathrm{mg} / \mathrm{mL}$, Tween-20 $2 \mathrm{mg} / \mathrm{mL}$, and Tris- $\mathrm{HCl} 0.05 \mathrm{M} \mathrm{pH} 8$ ). After $2 \mathrm{~h}$ incubation at $37^{\circ} \mathrm{C}$, wells were emptied and washed as explained before and filled again with aliquots of $100 \mu \mathrm{L}$ each, which contained rabbit IgGs anti- rBamSP_1, rBamMP_1, and rBamPLA2_1, serially diluted and prepared in incubation buffer (Tris- $\mathrm{HC} 0.05 \mathrm{M}, \mathrm{pH} 8$, gelatin $1 \mathrm{mg} / \mathrm{mL}$ and $\mathrm{NaCl} 0.5 \mathrm{M}$ ). The first dilution was 1:30, and the incubation time was $1 \mathrm{~h}$ at $37^{\circ} \mathrm{C}$. After washing, the bound rabbit IgGs were allowed to react with $100 \mu \mathrm{L}$ per well of $0.1 \mathrm{mg} / \mathrm{mL}$ of anti-rabbit IgGs, labeled with horseradish peroxidase (Merck KGaA, Darmstadt, Germany), prepared in incubation buffer. After one hour of incubation at $37^{\circ} \mathrm{C}$, wells were emptied, washed, and refilled with $100 \mu \mathrm{L}$ of the solution ABTS (Roche, Basel, Switzerland), which was the peroxidase substrate. The reaction of color development was halted by the addition of $25 \mu \mathrm{L}$ of SDS (20\%), and the samples were read at $405 \mathrm{~nm}$ in a Microplate Reader (Tecan Sunrise IVD version, Tecan Trading AG, Switzerland). Data were analyzed by nonlinear regression using the sigmoidal dose-response equation from the Prism program (Graphpad Prism v. 6.0c, San Diego, CA, USA). Conventional titers were calculated from the midpoint of the curve and correspond to the IgGs dilution for half of the maximal binding, which was considered as the half-maximal effective concentration (EC50).

\subsection{Phospholipase Activity}

The phospholipase A2 activity in the venom B. ammodytoides was measured in the absence and presence of rabbit serum immunoglobulins hyperimmunized with the mixture of the three recombinant enzymes, rBamSP_1, rBamMP_1, and rBamPLA 2 . It was indirectly monitored by titration of fatty acids with $\mathrm{NaOH}$ as a result of the hydrolysis of egg yolk phospholipids caused by the Bothrops venom. The activity was represented as $\mu \mathrm{mol}$ of $\mathrm{NaOH} / \mathrm{min}^{*} \mathrm{mg}$ of the enzyme, as describe by Shiloah et al. [19].

\subsection{Protease Activity Using Gelatine Zymography}

Briefly, the electrophoresis system described by Laemmli (1970) [20] was modified only by the presence of gelatin, which was co-polymerized within the separating gel in a concentration of $1.5 \mathrm{mg} / \mathrm{mL}$. After electrophoresis, the gel was incubated with $50 \mathrm{~mL}$ of the buffer solution of Tris- $\mathrm{HCl} 0.1 \mathrm{M}$, Triton $\mathrm{X}-1005 \%$, pH 8, for one hour. Afterward, the gel was rewashed with the same buffer but including only Triton X-100 at $0.05 \%$ and incubated for another hour. Finally, the gel was incubated in the buffer without Triton X-100 for one more hour. Later, the gel was incubated inside a humid container overnight at room temperature, and then dyed with Coomassie brilliant blue G 250 for one hour. 
At last, it was distained with acetic acid 10\% plus isopropanol 10\%. The whole venom of Bothrops asper was used as a positive control.

\subsection{Immunoaffinity Chromatography}

The previous rabbit-derived immunoglobulins containing $50 \mathrm{mg} / \mathrm{mL}$ were used to prepare affinity chromatography columns with Sepharose $4 \mathrm{~B}$ resin activated with cyanogen bromide (Sigma-Aldrich, Ontario, Canada) according to Pla et al. (2012) [21]. Once the venom was eluted from the affinity chromatography column, it was fractioned using an analytic C8 RP-HPLC column (5C8MS, $4.6 \times 250 \mathrm{~mm}$, Zorbax Agilent) using a linear gradient with solvent A (trifluoroacetic acid (TFA) $0.1 \%$, in water) and solvent B (TFA $0.1 \%$ in acetonitrile). The linear gradient was conducted from 0 to $60 \%$ solvent B, for $60 \mathrm{~min}$ at $1 \mathrm{~mL} / \mathrm{min}$, fractions were detected at $280 \mathrm{~nm}$, collected and immediately lyophilized. For protein identification, the samples were previously reduced with dithiothreitol (DTT, Sigma-Aldrich; St Louis, MO, USA), alkylated with iodoacetamide (Sigma-Aldrich) and digested "in solution" with Trypsin (Promega Sequencing Grade Modified Trypsin; Madison, WI, USA). The polypeptides generated by the enzymatic cleavage were desalted with Zip-Tip C18 (Millipore; Billerica, MA, USA) and injected to an LC-MS system composed of an EASY-nLC II nanoflow pump (Thermo-Fisher Co; San Jose, CA, USA) coupled to a LTQ-Orbitrap Velos MS (Thermo-Fisher Co, San Jose, CA, USA) with a nano-electrospray ionization (ESI) source. The total ion scanning (full scan) was performed on the Orbitrap analyzer with a resolution power of mass (RP Power; RP $=\mathrm{m} / \mathrm{FWHM}$ ) of 60,000. Peptide fragmentation was performed using the methods of CID (collision-induced dissociation) and HCD (high-energy collision dissociation). All spectra were acquired in positive detection mode. The execution and capture of the fragmentation data were performed depending on the total ion scan according to the pre-determined charges (only ions with a $\mathrm{z} 2+, \mathrm{z} 3+$, and $\mathrm{z} 4+$ charge were fragmented) with an isolation width of $2.0(\mathrm{~m} / \mathrm{z})$, normalized collision energy of 35 arbitrary units, $Q$ activation of 0.250 , activation time of $10 \mathrm{~ms}$ and maximum injection time of $10 \mathrm{~ms}$ per micro-scan. Protein identification was performed with the spectrometric data in raw format in the Proteome Discoverer program 1.4.1.14 (Thermo-Fisher Co., San Jose, CA, USA) through the Sequest HT search engine. For the identity search, the bothrops.fasta (UniProt) protein database was used. A false discovery rate (FDR, minimum) of 0.01 and 0.05 (maximum) was applied in addition to the inverted database (Decoy database) as a tool of the "Percolator" validation program. The maximum tolerance of molecular mass difference of the precursor ion, when compared to the theoretical versus experimental values (precursor mass tolerance), was $20 \mathrm{ppm}$ and the tolerance for the fragments obtained by dissociation of the precursor ion (fragment mass tolerance) was 0.6 Da. For the automatic search, the following modifications were established: carbamidomethylation constants of cysteines (C) and variables, oxidation of methionines $(\mathrm{M})$, and deamination of asparagine $(\mathrm{N})$ and glutamine $(\mathrm{Q})$.

\subsection{Protecting Activity of Immunoglobulins}

Neutralizing activity of antibodies anti-rBamSP_1, rBamMP_1, and rBamPLA2_1 in vivo was developed according to the guidelines of our Institute Committee of Animal Welfare using the mouse as an animal model. For neutralization experiments, $3 \mathrm{LD}_{50}$ of whole $B$. ammodytoides venom was pre-incubated $30 \mathrm{~min}$ at $37^{\circ} \mathrm{C}$ with absence or presence of the rabbit antibodies $(6.4,9.2$, and $13 \mathrm{mg} / \mathrm{mL})$. Then groups $(\mathrm{n}=3)$ of male mice (CD-1, 18-20 g body weight) were injected by the intravenous route [16]. After $24 \mathrm{~h}$, mice conditions were observed.

\subsection{Statistics}

For statistics, the software Prism 4.0 (Graph Pad Inc., San Diego, CA, USA) was used. Results were expressed as mean and standard deviation, or as mean with $95 \%$ confidence intervals.

Supplementary Materials: The following are available online at http://www.mdpi.com/2072-6651/11/12/702/s1: Figure S1: Genetic construction used for the expression of the recombinant rBamSP_1 and rBamMP_1, and the structural elements added to the sequence of the recombinant toxin are shown (the BamHI and PstI sites as well as 
the stop codons are underlined). Figure S2: SDS-PAGE of rBamSP_1 and rBamMP_1 expressed in E. coli cells. A) kDa - Molecular weight markers; lane 1, cells without IPTG; lane 2, cells with IPTG; lane 3, supernatant; lane 4, unbound proteins; lane 5, first wash; lane 6, second wash; lanes 7-13, protein elutions. B) kDa - Molecular weight markers; lane 1, cells without IPTG; lane 2, cells with IPTG; lane 3, supernatant; lane 4, inclusion bodies; lane 5, unbound proteins; lane 6, first wash; lane 7, second wash; lanes 8-14, protein elutions. Figure S3: Mass spectrum of the recombinant proteins. A) rBamSP_1, the top spectrum comprises the raw data showing the total ion current (time vs. intensity), the bottom spectrum is the deconvoluted spectrum on the true mass scale after Xcalibur Windows NT PC data system processing. B) rBamMP_1, the top spectrum comprises the raw data showing the total ion current according to the charge ionization, the bottom spectrum is the deconvoluted spectrum also processed by Xcalibur Data Acquisition and Interpretation Software (see Materials and Methods). Figure S4: The first forward and the last reverse oligonucleotides used for rBamSP_1 and rBamMP_1 assembly. Table S1. Identification of proteins of by tandem mass spectrometry (MS/MS) indicating the percentage coverage.

Author Contributions: Conceptualization, H.C. and L.L.C.-G.; methodology, H.C., L.L.C.-G. and D.B.; formal analysis, G.C. and E.V.; investigation, H.C. and E.V.; resources, G.C.; writing-original draft preparation, E.V.; writing-review and editing, G.C. and E.V.; funding acquisition, G.C.

Funding: This research was funded by Dirección General de Asuntos del Personal Académico (DGAPA-UNAM) grant number IN203118 awarded to GC.

Acknowledgments: The mass spectrometry determination conducted by Fernando Zamudio is greatly acknowledged. Also, we acknowledge the technical assistant of Felipe Olvera for rabbit antibody purification and for immunoaffinity column preparation. Also, we acknowledge Adolfo de Roodt, DVM Vanessa Costa de Oliveira, and DVM Pablo Regner for their help during the extraction of the venom gland and B. ammodytoides venom supply. We additionally acknowledge to Paul Gaytán, M.C. Eugenio López-Bustos and Q.I. Santiago Becerra from Unidad de Síntesis y Secuenciación de ADN at Instituto de Biotecnología. The patent filling advice from artin Patiño and MBA Mario Trejo are also greatly acknowledged.

Conflicts of Interest: The authors declare no conflict of interest.

\section{References}

1. Kang, T.S.; Georgieva, D.; Genov, N.; Murakami, M.T.; Sinha, M.; Kumar, R.P.; Vrielink, A. Enzymatic toxins from snake venom: Structural characterization and mechanism of catalysis. FEBS J. 2011, 278, 4544-4576. [CrossRef] [PubMed]

2. de Roodt, A.R.; de Roodt, A.R.; Dolab, J.A.; Hajos, S.E.; Gould, E.; Dinápoli, H.; Troiano, J.C.; Amoroso, M. Some toxic and enzymatic activities of Bothrops ammodytoides (yarara nata) venom. Toxicon 2000, 38, 49-61. [CrossRef]

3. Waghmare, A.B.; Salvi, N.C.; Deopurkar, R.L.; Shenoy, P.A.; Sonpetkar, J.M. Evaluation of health status of horses immunized with snake venom and montanide adjuvants, IMS 3012 (nanoparticle), ISA 206 and ISA 35 (emulsion based) during polyvalent snake antivenom production: Hematological and biochemical assessment. Toxicon 2014, 82, 83-92. [CrossRef] [PubMed]

4. Gutierrez, J.M.; Lomonte, B. Phospholipases A2: Unveiling the secrets of a functionally versatile group of snake venom toxins. Toxicon 2013, 62, 27-39. [CrossRef] [PubMed]

5. Micsonai, A.; Wien, F.; Bulyáki, É.; Kun, J.; Moussong, É.; Lee, Y.H.; Kardos, J. BeStSel: A web server for accurate protein secondary structure prediction and fold recognition from the circular dichroism spectra. Nucleic Acids Res. 2018, 46, W315-W322. [CrossRef] [PubMed]

6. Scanu, A.M.; van Deenen, L.L.; de Haas, G.H. Optical rotatory dispersion and circular dichroism of phospholipase A2 and its zymogen from porcine pancreas. Biochim. Biophys. Acta. 1969, 181, 471-473. [CrossRef]

7. Clement, H.; Corzo, G.; Neri-Castro, E.; Arenas, I.; Hajos, S.; de Roodt, A.R.; Villegas, E. cDNA cloning, heterologous expression, protein folding and immunogenic properties of a phospholipase A2 from Bothrops ammodytoides venom. Protein Expr. Purif. 2019, 154, 33-43. [CrossRef] [PubMed]

8. de la Rosa, G.; Corrales-García, L.L.; Rodriguez-Ruiz, X.; López-Vera, E.; Corzo, G. Short-chain consensus alpha-neurotoxin: A synthetic 60-mer peptide with generic traits and enhanced immunogenic properties. Amino Acids 2018, 50, 885-895. [CrossRef] [PubMed]

9. Hernández-Salgado, K.; Estrada, G.; Olvera, A.; Coronas, F.I.; Possani, L.D.; Corzo, G. Heterologous expressed toxic and non-toxic peptide variants of toxin CssII are capable to produce neutralizing antibodies against the venom of the scorpion Centruroides suffusus suffusus. Immunol. Lett. 2009, 125, 93-99. [CrossRef] [PubMed] 
10. Olvera, A.; Ramos-Cerrillo, B.; Estévez, J.; Clement, H.; De Roodt, A.; Paniagua-Solís, J.; Alagón, A. North and South American Loxosceles spiders: Development of a polyvalent antivenom with recombinant sphingomyelinases D as antigens. Toxicon 2006, 48, 64-74. [CrossRef] [PubMed]

11. Sintiprungrat, K.; Chaisuriya, P.; Watcharatanyatip, K.; Ratanabanangkoon, K. Immunoaffinity chromatography in antivenomics studies: Various parameters that can affect the results. Toxicon 2016, 119, 129-139. [CrossRef] [PubMed]

12. Queiroz, G.P.; Pessoa, L.A.; Portaro, F.C.; Maria de Fátima, D.F.; Tambourgi, D.V. Interspecific variation in venom composition and toxicity of Brazilian snakes from Bothrops genus. Toxicon 2008, 52, 842-851. [CrossRef] [PubMed]

13. Segura, Á.; Herrera, M.; Villalta, M.; Vargas, M.; Uscanga-Reynell, A.; de León-Rosales, S.P.; León, G. Venom of Bothrops asper from Mexico and Costa Rica: Intraspecific variation and cross-neutralization by antivenoms. Toxicon 2012, 59, 158-162. [CrossRef] [PubMed]

14. Sanchez, E.F.; Freitas, T.V.; Ferreira-Alves, D.L.; Velarde, D.T.; Diniz, M.R.; Cordeiro, M.N.; Diniz, C.R. Biological activities of venoms from South American snakes. Toxicon 1992, 30, 95-103. [CrossRef]

15. Rojas, E.; Quesada, L.; Arce, V.; Lomonte, B.; Rojas, G.; Gutierrez, J.M. Neutralization of four Peruvian Bothrops sp. snake venoms by polyvalent antivenoms produced in Peru and Costa Rica: Preclinical assessment. Acta Trop. 2005, 93, 85-95. [CrossRef] [PubMed]

16. World Health Organization (WHO). WHO Guidelines for the Production Control and Regulation of Snake Antivenom Immunoglobulins; WHO Press: Geneva, Switzerland, 2016.

17. Clement, H.; de Oliveira, V.C.; Zamudio, F.Z.; Lago, N.R.; Valdez-Cruz, N.A.; Valle, M.B.; de Roodt, A.R. Isolation, amino acid sequence and biological characterization of an "aspartic-49" phospholipase $\mathrm{A}(2)$ from Bothrops (Rhinocerophis) ammodytoides venom. Toxicon 2012, 60, 1314-1323. [CrossRef] [PubMed]

18. Brodsky, Y.; Zhang, C.; Yigzaw, Y.; Vedantham, G. Caprylic acid precipitation method for impurity reduction: An alternative to conventional chromatography for monoclonal antibody purification. Biotechnol. Bioeng. 2012, 109, 2589-2598. [CrossRef] [PubMed]

19. Shiloah, J.; Klibansky, C.; de Vries, A. Phospholipase isoenzymes from Naja naja venom-I. Purification and partial characterization. Toxicon 1973, 11, 481-490. [CrossRef]

20. Laemmli, U.K. Cleavage of structural proteins during the assembly of the head of bacteriophage T4. Nature 1970, 227, 680-685. [CrossRef] [PubMed]

21. Pla, D.; Gutierrez, J.M.; Calvete, J.J. Second generation snake antivenomics: Comparing immunoaffinity and immunodepletion protocols. Toxicon 2012, 60, 688-699. [CrossRef] [PubMed] 